Ann. Zootech., I973, 22 (3), 327-331.

NOTE

\title{
EFFETS DE VARIATIONS DU NIVEAU ALIMENTAIRE DES VACHES ET DE LA CROISSANCE PONDÉRALE DES GÉNISSES AU MOMENT DE L'INSÉMINATION SUR LA FERTILITÉ
}

\author{
M. ROCHET ( $\left.{ }^{1}\right)$ \\ avec la collaboration technique \\ du personnel de l’Établissement Départemental de l'Élevage de l’Orne. 6Iooo Alençon \\ Station de Physiologie animale, \\ Ecole nationale supérieure agronomique, I. N.R. A., \\ 9. Place Viala, \\ 34060 Montpellier Cedex
}

\section{RÉSUMÉ}

Dans le cadre d'une étude mise en place par l'Établissement départemental de l'Élevage de l'Orne ont été analysées :

- Lej conséqueaces d'un apport de $2 \mathrm{~kg}$ d'aliments concentrés par jour, pendant 15 jours après l'insémination, à des vaches de race Normande appartenant à des troupeaux dont la fertilité s'avér sit inférieure à la moyenne départementale: l'augmentation du niveau de la ration a amélioré de I5,9 p. Ioo (77,3 p. Ioo contre 6r,4 p. Ioo) le taux de fertilité, l'effet étant marqué dans les lots recevant moins de I3 UF par animal et par jour.

- Les relations existant entre le poids, ou les variations pondérales, précédant et encadrant l'insémination et la fertilité des génisses de race Normande : l'accélération de la croissance pendant la période entourant l'insémination n'a amélioré la fertilité que lorsque la vitesse de croissance pendant li période qui précède est inférieure à $75^{\circ} \mathrm{g} /$ jour environ.

\section{INTRODUCTION}

Les effets du niveau alimentaire et de ses variations, avant ou après l'insémination, sur la fertilité des femelles bovines, évaluée à partir du pourcentage de non-retours à 60-9o jours, étaient jusqu'à ces dernières années relativement mal connus. Récemment, certains chercheurs

(1) Adresse actuelle : Établissement Départemental de l'Élevage de l'Orne. B. P. 36 6rooo, Alençon. 
ont analysé ces phénomènes en appréciant le nivełu alimentaire, soit d'une manière indirecte en suivant la persistance de la lactation (BRochar'T, I966) ou l'évolution pondérale après le vêlage (WILTBANK et al., I964, KING, I968), soit d'une manière directe, en station expérimentale, avec des effectifs plus réduits (Wiltbank et al., i964, Blakely et al., 1963). Ces études tendent à montrer qu'une variation du niveau des apports énergétiques, avant l'insémination, affecte la fertilité.

Après l'insémination il semble qu'une modification du niveau alimentaire influence aussi la fertilité. Ce phénomène déjà observé chez la Ratte (BERG, 1965, 1967) a été également étudié chez la Vache (Girou et Brochart, I970; Brochart, Gaulliard et Girou, I972). Cette période serait particulièrement critique chez la Vache où la mortalité embryonnaire est relativement importante (GRADEN et al., 1968).

Chez les génisses, aucune étude sur l'influence des variations du niveau alimentaire, avant et après l'insémination, n'a été réalisée à notre connaissance.

Nous nous sommes proposé d'étudier sur des animaux répartis dans diverses exploitations :

- L'efficacité d'une alimentation complémentaire après l'insémination de vaches laitières. Cet essai a été réalisé dans l'Orne, région très différente du Jura où elle fut expérimentée avec succès par Girou et Brochart (1970).

- Les effets des variations de la croissance pondérale, avant et après l'insémination, chez la Génisse.

\section{MATÉRIEI ET MÉTHODES}

La première expérience a porté sur 176 vaches en lactation, de race Normande, réparties dans 53 exploitations inscrites au contrôle laitier, et ayant une fertilité inférieure à la moyenne départementale $(6 \mathrm{I}, 9 \mathrm{p}$. I 00 contre $69 \mathrm{p}$. I oo). Ces animaux recevaient une ration à base d'ensilage de maîs et de concentré. Dans chacune des exploitations, suivant une répartition au hasard, nous avions autant de vaches recevant dès le jour de l'insémination et pendant 5 jours un aliment concentré $\left(\mathrm{I}, \mathrm{O}_{5} \mathrm{UF} / \mathrm{kg}\right.$ et $\mathrm{I}_{4} 6 \mathrm{~g}$ de MAD/UF), à raison de $2 \mathrm{~kg} / \mathrm{jour}$, que de vaches témoins. L'étude a été réalisée au cours de la période hivernale où l'alimentation est plus facile à contrôler qu'au pâturage.

Les données concernant la fertilité ont été recueillies au moyen de plannings de fécondité mis en place par l'Établissement dép.rtemental de l'Élevage (E. D. E.). Les relevés (dates de vêlage et d'insémination) étaient contrôlées périodiquement. Le critère de fertilité est le taux de non retours à 60-90 jours a près la première insémination.

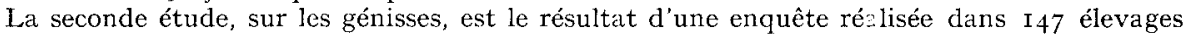
adhérents au syndicat de contrôle de croissance; celle-ci nous a permis d'obtenir les poids vifs et les vitesses de croissance de génisses pesées tous les 3 mois. Nous avons tenu compte des gains de poids moyens quotidiens a cours des 3 mois précédent l'insémination $\left(\mathrm{C}_{1}\right)$ et pendant 3 mois qui encadrent l'insémination $\left(\mathrm{C}_{2}\right)$. Il faut préciser, en fin, que go $\mathrm{P}$. I oo des inséminations des génisses ont été effectuées de la mi-janvier à la mi-mars.

\section{RÉSULTATS}

\section{A. - Expérience sur les vaches en lactation}

La modification du taux de fertilité obtenue par l'augmentation du niveau alimentaire après l'insémination figure au tableau $\mathbf{I}$.

L'efficacité de cette complémentation est différente suivant le niveau énergétique de la ration. Ainsi, elle ne semble bonne que pour des niveaux inférieurs à environ I 3 UF et elle est nulle. 
TABLEAU I

Effets d'une augmentation du niveau alimentaire sur la fertilité de vaches en lactation

\begin{tabular}{|c|c|c|c|c|c|}
\hline Lots & Effectifs & $\begin{array}{c}\text { Taux de fertilité } \\
\%\end{array}$ & $\begin{array}{l}\text { Niveau énergétique } \\
\text { de la ration (UF) }\end{array}$ & Effectifs & $\begin{array}{c}\text { Taux de fertilité } \\
\%\end{array}$ \\
\hline \multirow{2}{*}{ Témoin } & \multirow{2}{*}{88} & \multirow{2}{*}{$61,4 \quad(1)$} & $<13$ & 72 & $56,9 \quad(3)$ \\
\hline & & & $\geqslant 13$ & 16 & 75 \\
\hline \multirow{2}{*}{ Complémenté* } & \multirow{2}{*}{88} & \multirow{2}{*}{$77,3 \quad(2)$} & $<13$ & 70 & $78,6 \quad(4)$ \\
\hline & & & $\geqslant 13$ & 18 & 72,2 \\
\hline
\end{tabular}

* Apport de $2 \mathrm{~kg}$ de concentré par jour en plus de la ration.

La différence (2) - (1) est significative au seuil de 0,05 .
- -
(4) $-(3)-$
- de 0,01 .

\section{B. - Étude chez les génisses}

Lorsqu'il y a augmentation du gain de poids moyen quotidien pendant la période encadrant l'insémination par rapport à la période la précédant, la fertilité est globalement accrue (tabl. 2). Mais cette amélioration de la fertilité n'est observée que chez les animaux ayant une faible vitesse de croissance pendant la première période d'observation $\left(\mathrm{C}_{1}<750 / \mathrm{g} / \mathrm{jour}\right)$.

Chez les génisses ayant une vitesse de croissance élevée avant l'insémination, on observe une tendance inverse, bien que non significative. Cette tendance semble résulter d'un engraissement excessif puisque le poids moyen au moment de l'insémination des génisses gestantes après une insémination est inférieur au poids moyen de femelles ayant nécessité plusieurs inséminations $(428 \mathrm{~kg}$ contre $439 \mathrm{~kg}, p<0,05)$.

\section{TABLEAU 2}

Effets des variations de la vitesse de croissance sur la fertilité chez les génisses

\begin{tabular}{|c|c|c|c|c|c|}
\hline $\begin{array}{l}\text { Gain de poids } \\
\text { moyen quotidien* }\end{array}$ & Effectifs & $\begin{array}{c}\text { Taux de fertilité } \\
(\%)\end{array}$ & $\begin{array}{c}\text { Croissance } \\
(\mathrm{g} / \mathrm{j})\end{array}$ & Effectifs & $\begin{array}{c}\text { Taux de fertilité } \\
(\%)\end{array}$ \\
\hline \multirow{2}{*}{$\mathrm{C}_{2} \geqslant \mathrm{C}_{1}$} & \multirow{2}{*}{111} & \multirow{2}{*}{77,5} & $C_{1}<750$ & 97 & $80,4 \quad(1)$ \\
\hline & & & $C_{1} \geqslant 750$ & 14 & 57,1 \\
\hline \multirow{2}{*}{$C_{2}<C_{1}$} & \multirow{2}{*}{228} & \multirow{2}{*}{66,7} & $\mathrm{C}_{1}<750$ & 156 & $65,4 \quad(2)$ \\
\hline & & & $C_{1} \geqslant 750$ & 72 & 69,4 \\
\hline
\end{tabular}

* $\mathrm{C}_{1}$ correspond au gain moyen quotidien pendant une période de 3 mois avant l'insémination. $\mathrm{C}_{2}$ correspond au gain moyen quotidien pendant une période de 3 mois encadrant l'insémination. La différence (1) - (2) est significative au seuil de 0,01 . 


\section{CONCLUSIONS}

Notre étude a mis en évidence, dans le cadre où elle se déroulait, qu'un apport complémentaire de $2 \mathrm{~kg}$ de concentré pendant $\mathrm{I} 5$ jours, après l'insémination, à des vaches laitières améliore la fertilité lorsque le niveau énergétique de la ration est inférieur à I 3 UF environ. Au-dessus de ce niveau la fertilité n'est pas améliorée.

Ces résultats vont dans le même sens que ceux de Grrou et Brochart (1970), bien qu'il s'agisse chez ces auteurs d'un cheptel différent et de conditions d'apports différentes $(3 \mathrm{~kg}$ pendant 6 jours après l'insémination). Ces auteurs avaient trouvé un effet favorable pour les vaches présentant une carence énergétique supérieure à I UF.

L'étude sur les génisses montre que l'augmentation de la vitesse de croissance, qui traduit très vraisemblablement une amélioration du niveau alimentaire avant et après l'insémination, a un effet favorable sur la fertilité si la croissance pendant la période précédente est inférieure à $750 \mathrm{~g} /$ jour environ.

Reçu pour publication en mars 1973.

\section{SUMMARY}

\section{FERTILITY OF COWS AND HEIFERS AS AFFECTED BY VARIATIONS IN THE FEEDING LEVEL AT THE MOMENT OF INSEMINATION.}

According to the research programme decided by the Breeding Organization of the Department of Orne, the following criteria have been analyzed :

- Consequences of offering $2 \mathrm{~kg}$ concentrate feeds per day, for I 5 days after insemination, to cows of the Norman breed belonging to herds whose fertility appeared to be lower than that of the average value of the Department. Raising the feeding level of the diet improved the fertility rate by I5. p. Ioo (77 p. I0o versus 6 I.4 P. I00), the effect being marked in groups receiving less than $\mathrm{I}_{3} \mathrm{FU}$ per animal and per day.

- Relationships between weight, or variations of the latter, before, during and after insemination and fertility of heifers of the Norman breed. Increase of the growth rate during and after the period of insemination only improved the fertility when the growth rate prior to insemination was lower than about $75^{\circ} \mathrm{g} / \mathrm{day}$.

\section{RÉFÉRENCES BIBLIOGRAPHIQUES}

BERG B. N., I965. Dietary restriction and reproduction in the rat. J. Nutr. 87, 344-348.

BERG B. N., 1967. Maintenance of pregnancy in protein deprived rats by transitory protein supplements during early gestation. $J$. Nutr., 92, 66-70.

Blakely J. E., Thompson G. B., Brooks J. R., Stufflebeam C. E., Lasley J. F., 1963. Effects of nutrition on reproduction and physiology in heifers. J. Anim. Sci. 22, I 136.

Brochart M., 1966. Fertilité des vaches laitières et persistance de la lactation. C. R. Acad. Agric. 52, 915-9I9.

Brochart M., Gaulliard D., Girou R., 1972. Niveau calorico-azoté, flushing post-œstral et fertilité des vaches laitières. Bull. Tech. C.R. Z.V. Theix, no 9, 57-60.

Girou R., Brochart M., ig7o. Niveau énergétique, protéique et fécondité des vaches laitières. I. Influence d'une supplémentation alimentaire post-cestrale. Ann. Zootech. 19, 67-73. 
Girou R., Brochart M., I97o. Niveau énergétique, protéique et fécondité des vaches laitières. II. Effet d'une supplémentation alimentaire de brève durée sur la venue en chaleur de vaches en anœstrus post-partum. Ann. Zootech. 19, 75-77.

Graden A. P., Durward O. L. S., Mochow C. R. Mutter L. R., 1968. Causes of fertilization failure in repeat breeding cattle. J.Dairy Sci., 51, 77u- $\delta \mathrm{I}$.

KING, I968. The relation between the conception rate and changes on body-weight. Vet. Rec. 83, 492-494.

Wiltbank J. N., Rowden W. W., InGalls J. E., Zimmerman P. R., I964. Influence of post-partum energy level on reproductive performance of Hereford cows restricted in energy intake prior to claving. J. Anim. Sci. 23, ro49-ro53. 